\title{
LA REFLEXIÓN TRASCENDENTAL DEL LENGUAJE EN LA FACULTAD DE JUZGAR REFLEXIONANTE
}

DANIEL LESERRE

CONSEJO NACIONAL dE INVESTIGACIONES CiENTificas

ARGENTINA

"Facultad de juzgar reflexionante estética" es el concepto teórico articulador de la primera parte de la Crítica de la facultad de juzgar. Dentro de este contexto en el $\S 59$ aparece una de las escasas referencias explícitas al lenguaje en la obra kantiana. En este trabajo analizaré la significación de la exposición de la facultad de juzgar reflexionante estética para la discusión respecto del problema del lenguaje en Kant. ${ }^{1}$ Indicaré cómo en el desarrollo de la facultad de juzgar reflexionante estética, especialmente en los $\S \S 59$ y 60, Kant explicita una reflexión sobre el lenguaje desde el punto de vista trascendental. Con respecto al concepto de reflexión Kant afirma: la "reflexión (reflexio) no se ocupa con los objetos mismos" sino que se refiere a "las condiciones subjetivas bajo las cuales podemos obtener conceptos", ella es "la conciencia de la relación que existe entre representaciones dadas y nuestras diferentes fuentes de conocimiento". ${ }^{2}$ A partir de ello emplearé entonces el término "reflexión" para indicar la concepción de Kant respecto del lenguaje, cuya determinación teórica última es filosófico-trascendental.

\section{El problema del lenguaje en Kant}

Desde hace ya algo más de tres décadas se ha abierto una discusión que conjuga la filosofía trascendental kantiana con la filosofía del lenguaje ac-

1 Por cierto, sa debe recordar como inicio de la argumentación la diferencia entre facultad de juzgar determinante y reflexionante; $C f r . K U, \mathrm{~B} X X V-X X V I$. Cito la Crítica de la razón pura y la Crítica de la facultad de juzgar en la versión B, respectivamente según: I. Kant, Kritik der reiner Vernunft (KrV), F. Meiner, Hamburgo, 1956 e I. Kant, Kritik der Urteilkscraft (KU), F. Meiner, Hamburgo, 1974. A las otras obras de Kant me refiero según: I. Kant, Gesammelte Schiriften, Preussischen Akademie der Wissenschaften, Berlín, 1902-1910; Berlín, 1968-1977. (Vorlesungen ed. von der Akademie der Wissenschaften zu Göttingen, vol. 24 ss.), citando: AA. tomo, página.

${ }^{2} \mathrm{KrV}$, B 316. 
tual; en ella el concepto de lenguaje tiene un lugar central. ${ }^{3}$ En la reflexión filosófica actual el lenguaje no es exclusivamente el objeto particular de un conjunto de disciplinas igualmente particulares, sino que es visto como un "supuesto" o "condición trascendental". ${ }^{4}$ En este sentido se ha hablado de un "giro lingüístico" de la reflexión filosófica o de una "transformación de la filosofía" orientada "lingüísticamente". 5 Esto llevó también a plantear la posibilidad de una continuidad del programa filosófico de la "crítica de la razón" en el de una "crítica del lenguaje"; la función trascendental de la razón desarrollada en la filosofía de Kant devino, de este modo, en función "trascendental" del lenguaje. Uno de los motivos que alentó este punto de vista fue el alegado paralelismo entre el pensamiento crítico y la reflexión de L. Wittgenstein quien concibió su investigación "no dirigida a los fenómenos, sino [... ] a las 'posibililades' de los fenómenos" 6 Wittgenstein, de este modo, habría transladado reinterpretándolo "el idealismo trascendental de Kant del plano de la razón al plano del lenguaje". 7 Así, quedó abierta la posibilidad de examinar la filosofía crítica desde esta nueva óptica. La ausencia de desarrollos explícitos acerca del lenguaje llevó en un primer momento, a hablar del "silencio de Kant" al respecto ${ }^{8}$ Con ello quedó planteado, entonces, "el problema del lenguaje" en Kant. ${ }^{9}$ Éste ha sido abordado y desarrollado de diferentes maneras en el marco de la reflexión trascendental contemporánea de orientación kantiana. En ella encontramos un conjunto

3 Tomo como expresión de esta argumentación: E. Stenius "Wittgenstein as a Kantian Philosopher”, en Wittgenstein's Tractatus, Cornell U. Press, Nueva York, 1960, pp. 214-226.

4 Cfr. J. Simon, Philosophie und linguistische Theorie, Berlín-Nueva York, 1971, pp. 13-21.

5 R. Rorty (ed.), The Linguistic Turn, Chicago-Londres, 1967 y K-O. Apel, Transformation der Philosohie, Francfort, 1976, respectivamente.

6 L. Wittgenstein, Philosophische Untersuchungen, Francfort, 1960, $§ 90$, p. 337.

7 W. Stegmüller, Hauptströmungen der Gegenwartsphilosophie, 6a. ed., Stuttgart, 1978, p. 555. Un panorama de los trabajos acerca de esta relación se halla en S.M. Engel "Wittgenstein and Kant", en Philosophy and Phenomenological Research, no. 30, 1969-1970, pp. 483513; también: Susanne From, Wittgensteins Erkenntnisspiele contra Kants Erkenntnislehrse, Friburgo-Munich, 1979.

8 La expresión ha sido empleada por T. de Mauro para referirse precisamente a la actitud de Kant respecto del lenguaje: T. de Mauro, Introduzione alla semantica, Bari, 1966, pp. 63-66.

9 Respecto del problema del lenguaje en Kant: J. Simon, op. cit., pp. 1-12 y 44-49; M. Riedel, "Kritik der reinen Vernunft und Sprache, Zum Kategorienproblem bei Kant", en Allgemeine Zeitschrift für Philosophie, no. 3, 1982, pp. 1-17 y D. Markis "Das Problem der Sprache bei Kant", en Brigitte Scheer-G. Wohlfart (eds.), Dimensionen der Sprache in der Philosophie des Deutschen Idealismus, Würzburg, 1982, pp. 110-153. Más recientemente: M. Ujvári "Why Kantian Trascendental Philosophy cannot be a Methaphysical Foundation to Analysis of Language?", en Kant-Studien, no. 80, 1989, pp. 186-196; I. Kopzev "Kant und die transzendentalen Motive in der Sprache", en G. Funke (ed.) Akten des Siebenten Internazionalen Kant-Kongresses, Bonn, 1991, pp. 143-147; y J. Simon "Kant", en T. Borsche (ed.), Klassiker der Sprachphilosophie, Munich, 1996, pp. 233-256. 
de elaboraciones que han tomado justamente como motivo central el problema del lenguaje para la reflexión trascendental. Ellas pueden ser ordenadas en un espectro de posiciones que van desde el planteo ya mencionado de una reforma radical de la filosofía trascendental, de una "transformación" de la misma, guiada por la idea de lenguaje, tal como la propone $\mathrm{K}-\mathrm{O}$. Apel, hasta reinterpretaciones de la filosofía trascendental como "metacrítica" de la filosofía "lingüística" tal como la desarrolla J. Simon. ${ }^{10}$

A pesar de todas estas elaboraciones, el "problema" del lenguaje en Kant parece estar aún vigente. En este sentido se sigue hablando respecto de la reflexión acerca del lenguaje de un "lugar" en el sistema kantiano, "lugar que se abre en él para su despliegue ulterior y al cual sin embargo el mismo Kant, como muchos otros lugares, dejó vacío". ${ }^{11}$ A su vez, si bien "apenas sería esperable" que Kant fuera incluido en la actualidad entre los autores "clásicos de la filosofía del lenguaje", aparece sin embargo como tal. ${ }^{12} \mathrm{Ya}$ que si bien en él no se encuentra una "filosofía del lenguaje elaborada", sin embargo "ningún filósofo de la época moderna ha tenido una influencia tan grande en la filosofía del lenguaje"; ${ }^{13}$ tal influencia es aún tema de análisis. Ambas indicaciones muestran en consecuencia que la discusión no se halla cerrada. Por ello la determinación y exposición de la posición de Kant respecto del lenguaje en su marco histórico-conceptual propio es aún hoy una tarea que no ha hallado una solución tal que permita excluir la posibilidad de sostener con aparente parecida legitimidad interpretaciones contrapuestas. Es precisamente en este punto de la discusión donde quisiera intervenir este trabajo; en particular a través de la argumentación sostenida en la Crítica

10 Cfr. J. Simon, Philosophie und linguistische Theorie, Berlín-Nueva York, 1971, pp. 4549. En el marco de esta discusión W. Hogrebe analiza el valor que la filosofía de Kant puede tener para una elaboración de las cuestiones fundamentales en la actual filosofía del lenguaje, particularmente en lo referente a la teoria del significado (W. Hogrebe, Kant und das Problem einer transzendentaler Semantik, Friburgo, 1974); F Kaulbach subraya la conexión existente entre acción y lenguaje (F. Kaulbach, Das Prinzip Handlug in der Philosophie Kants, BerlínNueva York, 1978); G . Schönrich a su vez brinda una reinterpretación de la filosofía kantiana en relación con la actual filosofía del lenguaje (G. Schönrich, Kategorien üd Transzendentalen Argumentation. Kant und die Idee einer transzendentalen Semiotik, Francfort, 1981).

11 G. Prauss, Die Welt und wir, vol. I, no. 1: Sprache-Subjekt-Zeit, Stuttgart, 1990, pp. 6566.

12 T. Borsche, "Einleitung", en T. Borche (ed.), Klassiker der Sprachphilosophie, Munich, 1996, p. 13.

13 J. Simon, "Kant", en T. Borsche (ed.), Klassiker der Sprachphilosophie, Munich, 1996, p. 233. Como se ve este punto de vista confirma la ligazón entre el pensamiento crítico y el "giro lingüístico". En este sentido ha sostenido Lewis White Beck que "el giro lingüístico de las últimas décadas es una ampliación del giro copernicano", L. White Beck "Was haben wir von Kant gelemt", en Kant-Studien, no. 72, 1981, p. 5. 
de la facultad de juzgar, ya que ella brinda una oportunidad para replantear esta cuestión. ${ }^{14} \mathrm{De}$ acuerdo con ello me propongo a continuación:

1) reconsiderar desde este punto de vista algunos aspectos de dos de los conceptos desarrollados por Kant en dicho marco: simbolismo y comunicación, ya que ellos constituyen una pieza clave para determinar la concepción explícita que Kant tuvo del lenguaje;

2) subrayar el carácter trascendental de esta concepción; ya que con ello lo que en un principio puede aparecer como observaciones relativamente marginales se muestran como elementos de una concepción unitaria; ${ }^{15}$ la cual, finalmente, se muestra como una posición filosófica respecto del lenguaje.

\section{Simbolismo y esquematismo}

La consideración del lenguaje en el $\S 59$ se ubica en el marco de la relación entre concepto e intuición, su inicio indica claramente el problema que nos va a ocupar:

Para exhibir la realidad de nuestros conceptos se exigen siempre intuiciones. Si los conceptos son empíricos, entonces llámanse la intuiciones ejemplos; si son conceptos puros del entendimiento, llámanse esquemas; si se pide que se exhiba la realidad objetiva de los conceptos de la razón, es decir, de las ideas y ello para el conocimiento teórico de las mismas, entonces se desea algo imposible porque no puede, de ningún modo, darse intuición alguna que les sea adecuada. ${ }^{16}$

14 La importancia de la Crítica de la facultad de juzgar para la determinación de la reflexión kantiana sobre el lenguaje ha sido ya objeto de detenida consideración: W. Biemel, Die Bedeutung von Kants Begründung der Asthetik für die Philosophie der Kunst, Köln, 1959, pp. 74, 81 y 122; H. Gadamer, Warheit und Methode, Tubinga, 1960, pp. 31-71; B. Liebrucks, Sprache und Bewußtsein, vol. 4: Die erste Revolution der Denkungsart, Francfort del Main, 1968, pp. 465 y ss., 488 y ss; y J. Caravajal Cordón "El lenguaje como problema filosófico y Crítica del Juicio", en R. Aramayo y G. Vilar (eds.), En la cumbre del criticismo, Barcelona, 1992, pp. 46-77.

15 Marc Wogau subraya en general el carácter trascendental de la argumentación llevada a cabo en la Crítica de la facultad de juzgar; K. Marc-Wogau, Vier Studien Zu Kants Kritik der Urteilskraft, Leipzig, 1938, pp. xi-xii. Esta afirmación puede resultar trivial, pero es uno de los fundamentos que permiten sostener el carácter a su vez trascendental de la perspectiva de Kant respecto del lenguaje.

${ }^{16} K U$, B 254. Que se pueda "exhibir la realidad de nuestros conceptos" o la "realidad de objetiva" de ellos quiere decir, especialmente desde el punto de vista de nuestro análisis, mostrar su "significado objetivo" KrV, B 194-195 y B 242. Según G. Schönrich, Kant habría empleado implícitamente el concepto de significado como "concepto explicativo de la objetividad": G. Schönrich, Kategorien und Transzendentalen Argumentation. Kant und die Idee einer transzendentalen Semiotik, Francfort, 1981, p. 141. Precisamente en este sentido se puede recordar la observación de E. Adickes según la cual "significado" (Bedeutung) sería 
La determinación teórica del concepto de lenguaje se halla en la mutua relación entre concepto e intuición. Pero precisamente tal es el problema del posible significado de los conceptos. Las formas de procurarles significado a éstos son, desde la perspectiva trascendental, el esquematismo y el simbolismo. Tanto el carácter trascendental de la reflexión de Kant como su articulación teórica se muestran particularmente al ubicar esta reflexión, llevada a cabo en la Crítica de la facultad de juzgar, en relación con la Crítica de la razón pura. En la Crítica de la razón pura, precisamente en la deducción trascendental, el lenguaje es visto desde la función de unificación de la autoconciencia, como una forma de unificar representaciones. ${ }^{17}$ Según esto, las relaciones que se establecen en la conciencia de lenguaje, frente a la unidad objetiva de la autoconciencia, tienen un carácter empírico y contingente. Todo lo contrario ocurre con el concepto de significado en tanto se lo determina a partir del análisis del significado de los conceptos puros. En este sentido el concepto de significado sintetiza la perspectiva trascendental acerca del lenguaje en la Crítica de la razón pura. ${ }^{18}$ Partimos entonces, tal como lo indica el pasaje citado, de cómo los conceptos pueden alcanzar significado y de la comparación de las dos formas fundamentales de lograrlo: esquematismo y simbolismo.

Veamos, brevemente, la función del esquematismo. La doctrina kantiana del esquematismo surge, en primer término, como respuesta al problema clásico de la relación entre entendimiento y sensibilidad. El esquematismo es, en tanto producto de la imaginación, el modo de relacionar, en una perspectiva trascendental, entendimiento y sensibilidad. El esquema es "un procedimiento universal de la imaginación" a través del cual "se le suministra a un concepto su propia imagen". ${ }^{19}$ Ahora bien, el esquematismo comparte con el lenguaje ser un producto de la imaginación y servir como mediación entre entendimiento y sensibilidad, pero como función trascendental muestra su diferencia respecto de él. La doctrina del esquematismo, entonces, si bien no ofrece ningún "testimonio" directo acerca de la concepción del lenguaje en Kant, muestra una determinación de importancia respecto del "lugar" que se le asigna al lenguaje "entre" entendimiento y sensibilidad. Precisamente lenguaje y esquemas son productos de la imaginación, pero éstos, a diferencia de los signos del lenguaje, son el resultado

prácticamente equivalente a "sentido" (Sinn), "uso" (Gebrauch), "validez objetiva" (objective Gultigkeit), "contenido" (Inhalt) y "aplicabilidad" (Anwendbarkeit); E. Adickes, Kant und das Ding an sich, Berlín (1924), 1964, p. 82.

17 "Uno liga la representación de cierta palabra con una cosa, el otro, con otra cosa; y la unidad de la conciencia, en lo que es empírico, no es con respecto a lo que es dado, necesaria y universalmente válida." KrV, B 140.

18 Permítaseme aquí sólo indicar esta idea.

$19 \mathrm{KrV}$, B 179. 
de la imaginación trascendental; mientras que los signos se caracterizan por resultar de la asociación, cuyo carácter es empírico. Los esquemas son formas universales y necesarias de vincular concepto e intuición, la facultad de los signos, ${ }^{20}$ por su parte, sólo produce asociaciones diversas y contingentes, cuya estabilidad está dada por el hábito. Pero de este modo, por así decir, por contrapartida, la doctrina kantiana del esquematismo indica la reflexión de Kant acerca del lenguaje en perspectiva trascendental. La función de la doctrina del esquematismo para la reflexión acerca del lenguaje puede ser sintetizada del siguiente modo:

1) el esquematismo viņcula el entendimiento con la sensibilidad. Es, en tanto producto de la imaginación, el modo de relacionar, en una perspectiva trascendental, entendimiento y sensibilidad;

2) el esquematismo, al establecer un método de representación en la intuición "análogo" al de la matemática, lleva a plantear una comparación con el procedimiento matemático precisamente como forma de representación en la intuición, donde se relaciona el concepto con el caso particular donde éste se presenta; ${ }^{21}$

3) en tanto teoría del juicio, el esquematismo es una teoría del empleo de conceptos, es decir, del empleo de reglas. En tanto teoría trascendental del juicio debe poder señalar el caso a priori, lo que la caracteriza como tal. Y por ello ofrece el modelo del empleo de reglas en la perspectiva trascendental;

4) la doctrina kantiana del esquematismo es una pieza clave en la teoría del significado. En ella se establecen algunas de las condiciones sin las cuales los conceptos carecen de significado;

5) en parte por lo dicho, el esquematismo, ya desde las consideraciones críticas de J.G. Hamann y J.G. Herder a la Crítica de la razón pura, ha sido visto como el "lugar" de la teoría de Kant donde debía ubicarse la reflexión acerca del lenguaje; ${ }^{22}$

20 El lenguaje como facultad de designación es analizado por Kant en la Antropología en sentido pragmático, particularmente en el $\S 38$.

21 La interrelación entre el esquematismo, la construcción matemática y la exhibición a priori de un concepto en la intuición ha sido recientemente analizada por A. Ferrarin en "Construction and Mathematical Schematism. Kant on the Exhibition of a Concept in Intuition", en Kant-Studien, no. 86, 1995, pp. 131-174. Por mi parte, acorde con la perspectiva sostenida en este trabajo, sugiero que precisamente la doctrina kantiana del simbolismo debe ser incluida y considerada en esta interrelación. Ello muestra la articulación de la reflexión de Kant acerca del lenguaje con algunos de los conceptos centrales de la estructura teórica de la filosofía crítica.

22 Ambos conciben el esquematismo como el concepto kantiano que, en tanto instancia de mediación entre la sensibilidad y el entendimiento permite comprender la función del 
6) del mismo modo, el esquematismo ha sido considerado en la actualidad, junto con la doctrina de las categorías, como un aspecto central de la Crítica de la razón pura para la discusión en filosofía del lenguaje y epistemología.

El simbolismo, por su parte, desempeña una función semejante al esquematismo, su importancia como concepto teórico se muestra resaltada a través de este paralelismo. Desde el punto de vista de su función mediadora entre concepto e intuición la caracterización que acabamos de hacer del esquematismo se aplica al simbolismo, tal como veremos a continuación.

\section{El lenguaje en la perspectiva del simbolismo}

Concepto e intuición pueden relacionarse, entonces, de diferentes modos según el tipo de concepto del que se trate y de la forma según la cual se le brinde intuición. En el caso del esquematismo al concepto originado en el entendimiento le es dada a priori una intuición correspondiente; mientras que en el simbolismo, el concepto originado en la razón no encuentra intuición sensibie alguna que pueda corresponderle. Dada esta carencia de una intuición correspondiente que pueda ser subordinada al concepto por medio del esquema, la facultad de juicio procede entonces de una manera analógica. En el procedimiento analógico un concepto es referido a su posible objeto pero, en ausencia de una intuición correspondiente, esta referencia tiene lugar a través de otro concepto al cual sí le es dada una intuición. Este tipo de representación simbólica es intuitiva y no discursiva. Por ello, si bien en ciertas ocasiones Kant emplea el término "símbolo" en un sentido general, ${ }^{23}$ aquí aparece en su específica determinación trascendental. Por lo mismo, afirma Kant que "símbolo" en el sentido aquí tratado difiere del "admitido por los lógicos modernos", ${ }^{24}$ puesto que para ellos símbolos son:

lenguaje aun cuando Kant no planteara explícitamente esta equivalencia entre esquematismo y lenguaje. Herder propone una "metacrítica" de la filosofía kantiana, entendiendo por tal una crítica de la razón que estaría no meramente orientada al aspecto formal de la misma sino la determinación de los contenidos que podrían serle propios. Herder lleva a cabo este proyecto en su "metacrítica" de la Crítica de la razón pura de 1799; T.M. Seebohm "Der systematische Ort der Herderschen Metakritik", en Kant-Studien, no. 63, 1972, pp. 59-74. Hamann se refiere al lenguaje en relación con la "raíz común" de sensibilidad y entendimiento en su "Metacrítica acerca del purismo de la razón" donde él expone programáticamente su "crítica al criticismo". En J.G. Hamann, Sämtliche Werke, t. III, Wien, 1951, pp. 283-289.

${ }^{23}$ Así, por ejemplo, habla de "construcción simbólica" en el contexto de las operaciones matemáticas; $K r V, \mathrm{~B} 745$.

${ }^{24} K U, \mathrm{~B} 255$. 
meros caracteres, es decir, designaciones de los conceptos por medio de notas sensibles que los acompañan, y que no contienen nada que pertenezca a la intuición del objeto sino que sólo sirven a aquellos de medio de reproducción según la ley de la asociación de la imaginación, por lo tanto, en intención subjetiva; los tales son, o palabras, o signos visibles (algebraicos, y hasta mímicos) en tanto meras expresiones para conceptos. ${ }^{25}$

La representación simbólica es, como dijimos, intuitiva. La exhibición intuitiva de una representación puede ser entonces intuitiva en sentido propio o simbólica. Ambas son exhibiciones en todo el sentido del término, esto es, formas de presentar un objeto. Por referirse indirecta pero efectivamente a intuiciones, el procedimiento simbólico es considerado como una forma de "conocimiento intuitivo" que se opone al discursivo; y el símbolo es una forma de exhibición indirecta pero intuitiva: ${ }^{26}$

Todas las intuiciones que se ponen bajo conceptos a priori son esquemas o símbolos de los cuales los primeros contienen exhibiciones directas del concepto, los segundos indirectas. Los primeros hacen esto demostrativamente; los segundos por medio de una analogía (para la cual también se utilizan intuiciones empíricas). ${ }^{27}$

Los símbolos contienen exhibiciones indirectas por medio de la analogía. El símbolo adquiere de este modo significado, en relación con lo que puede pensarse a partir de él, a partir de lo que puede "verse" en él. ${ }^{28}$ Esto puede ejemplificarse a través de la observación kantiana respecto de la palabra "demostrativamente" (demonstrativ). Indica Kant que la emplea manteniendo, al menos parcialmente, el "significado de la palabra" según

${ }^{25} K U$, B 255. Esta idea es expresada también en la Antropología en sentido pragmático; cfr. I. Kant, Anthropologie in pragmatischer Hinsicht, AA, VII, 191.

${ }^{26}$ Según T. Todorov, Kant en la Crítica de la facultad de juzgar modifica el concepto mismo de "símbolo". Hasta ese momento "símbolo" significaba "o bien un simple sinónimo de una serie de términos empleados (como alegoría, jeroglífico, cifra, emblema, etc.), o bien designaba preferentemente el signo puramente arbitrario y abstracto (los símbolos matemáticos), siendo este segundo sentido corriente especialmente entre los leibnizianos". T. Todorov, Theories du Symbole, París, 1977, p. 236. En este contexto "Es Kant que en la Crítica de la facultad de juzgar transforma este uso y conduce la palabra símbolo muy cerca de su sentido moderno. Lejos de caracterizar la razón abstracta, el símbolo pertenece a la manera intuitiva y sensitiva de aprehender las cosas". Ibid.

$27 \mathrm{Ku}, \mathrm{B} 256$.

${ }^{28}$ El símbolo "no sólo pertenence a la esfera del logos" sino a la realidad sensible puesto que "no tiene su significado en la relación con otro significado, sino que su propio ser sensible tiene significado. Es, de un modo primordial aquello donde se puede conocer algo otro". $\mathrm{H}$. Gadamer, Wahrheit und Methode, Tubinga, 1960, p. 68. En él tiene lugar una "interconexión metafísica entre lo visible y lo invisible", H. Gadamer, op. cit., p. 69. 
el cual "demostrar (ostendere, exhibere)" significa "simultáneamente exhibir en la intuición" un concepto. ${ }^{29}$ De este modo, el símbolo tiene su "propio ser sensible", ${ }^{30}$ es exhibición y no meramente designación. ${ }^{31}$ Así, la representación en el lenguaje es comparada, al menos indirectamente, con la posibilidad de intuición que ofrece. En este sentido el simbolismo desempeña una función semejante al esquematismo. En el simbolismo se produce también una relación entre entendimiento y sensibilidad por medio de la imaginación, pero aquí por medio de la analogía. El modo de proceder en la forma simbólica de esquematizar se ve particularmente ilustrado por la analogía. La representación analógica se funda en la función de la capacidad reflexionante de juzgar (mientras que el esquematismo se realiza en la función determinante). En ella la capacidad de juzgar ejecuta una doble operación; en primer lugar aplica el concepto al objeto de una intuición y, en segundo término, yendo más allá de ésta, emplea la regla de la reflexión, aplicada en el primer caso, a otro objeto completamente distinto del cual el primer concepto es sólo un símbolo. El lenguaje como tal se configura según este procedimiento que relaciona concepto e intuición:

Nuestra lengua está llena de semejantes exhibiciones indirectas, según una analogía, en las cuales la expresión no encierra propiamente el esquema para el concepto, sino un símbolo para la reflexión.

Así, las palabras fundamento (apoyo, base), depender (ser tenido desde arriba), fluir de (en vez de seguirse), sustancia (el portador de los accidentes según se expresa Locke) e innumerables más, no son hipotiposis esquemáticas, sino simbólicas y son expresiones para conceptos, no por medio de una intuición directa, sino sólo según la analogía con la misma, es decir según la translación de la reflexión, de un objeto de la intuición, a otro concepto totalmente distinto, al cual quizá no pueda jamás corresponder una intuición. ${ }^{32}$

Kant ilustra el funcionamiento del lenguaje a través de ejemplos del léxico filosófico. En la palabra "fundamento" se sugiere la imagen de apoyo, de base; en "depender" la de estar sostenido desde arriba. La palabra "sustancia" induce la imagen del portador de algo. El lenguaje entonces, en tanto simbolismo, cumple con la función de volver sensible al concepto; brinda, por medio de imágenes asociadas analógicamente, un acceso a los conceptos puros. En tanto exposición simbólica el lenguaje brinda al concepto-que la razón sólo puede pensar- una integración específica ente estética (estética en el doble sentido del término) a través de la determinación analógica del

$29 K U, \mathrm{~B} 241$.

30 H. Gadamer, op. cit., p. 68.

31 Cfr. H. Gadamer, op. cit., p. 71.

$32 K U$, B 257. 
concepto. El lenguaje como tal suministra imágenes en las cuales se manifiesta lo inteligible. ${ }^{33}$ De este modo, bajo el título de simbolismo, se sintetiza una perspectiva unificadora de la reflexión kantiana sobre el lenguaje, la cual aparece aquí en el marco de la idea de una determinación inteligible del ser humano, a la cual se arriba a través de la "belleza como símbolo de la moralidad". ${ }^{34}$ Con ello se brinda indirectamente la descripción de un funcionamiento del lenguaje ya no meramente "intralingüístico" como la asociación sino con relación a la forma de otorgarle significado al concepto. Con ello se complementa la perspectiva acerca del significado tal como aparece en la Crítica de la razón pura. Pero, en tanto a través del símbolo no se llega a establecer un significado objetivo sino indirectamente una forma de intuición por medio de una analogía, queda abierta la posibilidad de perspectivas y de comunicación de las mismas. ${ }^{35}$

\section{La posibilidad de comunicación}

En la Crítica de la razón pura la reflexión trascendental sobre el lenguaje se lleva a cabo en relación con el concepto de significado, en la Crítica de la facultad de juzgar dicha reflexión se vincula al concepto de comunicación. Comunicación tampoco es un concepto estrictamente lingüístico sino que forma parte de la crítica trascendental, pero también él, al igual que el de significado, permite mostrar el valor del lenguaje desde tal perspectiva. Desde el punto de vista de la argumentación referida al lenguaje con el concepto de comunicación, la Crítica de la facultad juzgar retoma la cuestión allí donde la había dejado la Crítica de la razón pura:

Nada puede ser universalmente comunicado más que el conocimiento y la representación en cuanto pertenece al conocimiento. ${ }^{36}$

33 W. Flach afirma que "el lenguaje se recubre con el dominio de la representación intuitivosimbólica", op. cit., p. 458 y a partir de ello subraya la importancia del lenguaje como acceso a lo inteligible. Ve en ello una de las contribuciones de la doctrina kantiana de la exposición simbólica a la filosofía del lenguaje y la teoría de la ciencia literaria, op.it., pp. 458 y 459.

34 La noción de simbolismo brinda así una nueva perspectiva donde se reunifica la reflexión kantiana sobre el lenguaje. Ésta aparece ahora en el marco de la idea de una determinación inteligible del ser humano, es decir, en una perspectiva teleológica donde el concepto de símbolo en el cual se ordena la reflexión acerca del lenguaje mantiene un "trasfondo metafísico" que tiene lugar a través de la indicación del pasaje de lo sensible a lo suprasensible; $\mathrm{Cfr}$. $\mathrm{H}$. Gadamer, op. cit., p. 69.

35 Precisamente al referirse a la noción de analogía, concepto en el cual convergen la consideración acerca del lenguaje y de significado, afirma Kant que se trata de un tema apenas analizado aun cuando merecería una "profunda indagación", pero lo deja sin desarrollar; $K U$, B 257.

$36 K U$, B 27. 
En la Deducción trascendental en la Crítica de la razón pura se plantea la posibilidad de que los conceptos lleguen a tener realidad objetivad, es decir, lleguen a tener significado. Aquí, en la Crítica de la facultad de juzgar, se discute la posible objetividad, del juicio estético. En este caso, en tanto el juicio estético pretende una universalidad y necesidad para todo sujeto, también requiere una deducción, es decir, una legitimación que descanse en un principio a priori. Pero aquí, el resultado no es, precisamente, la objetividad, puesto que "el juicio de gusto determina su objeto", no ya como objetivo sino "como si fuese objetivo". ${ }^{37}$ Aquí la "intuición" está dada por la imaginación que "esquematiza sin concepto". ${ }^{38}$ De esta manera, resulta posible establecer desde el punto de vista de la reflexión acerca del lenguaje y el significado un paralelismo entre la deducción de los conceptos puros llevados a cabo en la Crítica de la razón pura y la deducción de juicios estéticos puros en la Crítica de la facultad de juzgar. En el primer caso el concepto central que se halla en juego (desde el punto de vista de la argumentación referida al lenguaje) es el de significado, mientras que en el segundo es el de comunicación.

La explicitación de la noción de expresión sirve como trasfondo al examen del concepto de comunicación, en el cual culmina el análisis del juicio estético. Por ello, con la finalidad de mostrar las implicaciones más salientes para una reflexión trascendental acerca del lenguaje contenidas en este argumento, analizaremos brevemente en primer lugar la noción de expresión y luego el límite en la comunicación de las ideas estéticas y la poesía.

El punto de vista del arte ofrece una visión integral de la perspectiva kantiana de la expresión (Ausdruck). Tres elementos la constituyen: las palabras, los gestos y el tono, lo que se corresponde correlativamente con tres acciones: articulación, gesticulación y modulación. Pero con ello se señala entonces que la comunicación no sólo está referida a conceptos ya que para poder "comunicarse tan perfectamente como sea posible" es necesario atender no sólo a los conceptos sino también a las sensaciones y a la intuición, es decir, a todos los aspectos presentes en la expresión, los que sólo conjuntamente configuran "la completa comunicación del hablante". ${ }^{39}$ Sobre

${ }^{37} \mathrm{KU}, \mathrm{B} 136$.

${ }^{38} \mathrm{KU}, \mathrm{B} 146$.

39 La caracterización kantiana de la expresión es la siguiente: "Ésta consiste en la palabra, el gesto y el sonido (articulación, gesticulación y modulación). Sólo la combinación de estos tres modos de la expresión constituye la completa comunicación del hablante. Pues pensamiento, intuición y sensación son, mediante ellos, simultánea y conjuntamente, transmitidos a los demás." KU, B 204-205.

Según Gadamer, el concepto dominante de expresión en el siglo xvm se halla dominado por el punto de vista de la comunicación y la comunicabilidad, por ello de lo que se trata es de encontrar la expresión, esto significa "buscar una expresión, que quiere alcanzar una 
esta base la comunicación es analizada desde el punto de vista de la posible comunicación de las ideas estéticas, las cuales no pueden ser integralmente expresadas por "ningún lenguaje". La posibilidad de comunicación universal plantea, entonces, los límites mismos del lenguaje: el de la expresión de lo inefable, tal como se manifiesta al tratar de comunicar las ideas estéticas. ${ }^{40}$ Éstas son representaciones de la imaginación que inducen al pensamiento sin poder, sin embargo, ser determinadas y precisadas en un concepto. Por ello "ningún lenguaje puede alcanzar plenamente" la idea estética y "hacerla comprensible". ${ }^{41}$ La reflexión sobre la idea estética señala el límite de una posibilidad de comunicación más allá del concepto, y con ello los "límites" del lenguaje. Ia idea estética comunica, da pie para pensar en "algo" más allá de lo que las palabras pueden expresar de su concepto, puesto que ella consiste en "atributos (estéticos) de un objeto cuyo concepto, como idea de la razón, no puede ser expuesto adecuadamente". ${ }^{42}$ La idea estética se halla asociada a representaciones como resultado del libre uso de la imaginación y al no encontrar una expresión que indique un determinado concepto:

hace, pues, que en un concepto pensemos muchas cosas innombrables, cuyo sentimiento vivifica las facultades de conocer, y se enlaza al lenguaje, en tanto mera letra. ${ }^{43}$

Ello aparece claramente en la poesía. Aquí la reflexión sobre el lenguaje tiene lugar en tanto éste se realiza como arte. Si bien la poesía sólo ofrece un juego de ideas, da vida, por medio de la imaginación, a los conceptos producidos por el entendimiento. Ella expresa las ideas estéticas por medio del lenguaje y, en este sentido, resume por excelencia (en cierto sentido "doblemente", como arte y como lenguaje) la exhibición simbólica que, común a todo arte, caracteriza como hemos visto, también al lenguaje.

impresión, por ello de ningún modo se trata de la expresión en el sentido de expresión de vivencias". H. Gadamer, op. cit., p. 475.

40 "Semejantes representaciones de la imaginación pueden ser llamadas ideas, por una parte porque, tienden, al menos, a algo que se halla sobre los límites de la experiencia, y así buscan aproximarse a una exhibición de los conceptos de la razón (de las ideas intelectuales), lo cual les da la apariencia de una realidad objetiva; por otro lado y, fundamentalmente, porque en cuanto intuiciones internas ningún concepto puede serles enteramente adecuado." $K U$, $\mathrm{B}$ 193-194

$41 K U, \mathrm{~B} 193$.

${ }^{42} \mathrm{KU}$, B 195. Los atributos estéticos "dan también una idea estética que, en lugar de la exhibición lógica de aquella idea de la razón, sirve propiamente para vivificar el alma en la medida en que le abre la perspectiva en un imprevisible campo de representaciones afines". $K U, \mathrm{~B} 195$.

${ }^{43} K U$, B 197. 
El arte en general, pero particularmente la poesía "da que pensar". ${ }^{44}$ El lenguaje poético permite comunicar una disposición subjetiva del ánimo y simultánemente manifestar el principio que le confiere vida: el espíritu. A partir de ello, entonces el lenguaje es visto en relación con la posibilidad de comunicación.

La analítica en la Crítíca de la razón pura mostró que no hay significado trascendental sino significado "para nosotros", que el mundo es común como significado objetivo para nosotros. La analítica de lo bello en la Crítica de la facultad de juzgar, muestra que sobre esa base objetiva, establecida en la Crítica de la razón pura, y "más allá" de ella se dan otras posibilidades de referirse a los "objetos", abiertas por la libertad. En ellas la subjetividad comunica perspectivas expresadas en el juicio de gusto. Pero esta posibilidad abierta en la reflexión acerca del arte no consiste meramente en la posibilidad de expresión de la subjetividad sino que pretende tener un fundamento, el cual se expresa en la universalidad postulada en el juicio de gusto. Ya que los juicios acerca de los objetos bellos, a diferencia de los juicios acerca de fenómenos que simplemente pueden ejercer un efecto agradable (y que, en consecuencia, sólo pueden pretender una validez privada) deben poder establecer una concordancia con los juicios de otros. Por ello, al juicio de gusto se le asocia con una pretensión de validez para todos, pero esta universalidad no se halla apoyada en objetos, sino que se halla ligada a "una pretensión de universalidad subjetiva." 45 Este juicio tiene, entonces, la tarea de combinar las dos características propias del juicio de conocimiento (universalidad y necesidad) con las que lo distinguen como juicio de gusto: subjetividad y falta de concepto. ${ }^{46}$ De este modo la argumentación acerca de la comunicación en la perspectiva de la Crítica de la facultad de juzgar parte del marco de la objetividad establecida, es decir, del significado establecido como conocimiento objetivo, pero para ir mas allá de la misma. De esta forma, la reflexión trascendental sobre el lenguaje pasa de consi-

44 En ella el pensamiento se daría, por así decir, cifrado. En este sentido la poesía sería una forma previa de reflexión. Esto puede ilustrarse con el siguiente pasaje de la Lógica: "Por lo demás los primeros filósofos expresaron todo en imágenes. Pues la poesía, que no es otra cosa que una expresión de los pensamientos en imágenes, es más antigua que la prosa. Por ello, al comienzo, incluso en las cosas que sólo son objeto de la razón pura, se tuvo que hacer uso del lenguaje de las imágenes y de la forma de escribir poética." Logik, AA, IX, 346.

${ }^{45} \mathrm{Cfr} . K U, \S 8$ "La universalidad de la satisfacción es representada en un juicio de gusto sólo como subjetiva."

46 "Subjetividad" quiere decir en primer lugar una delimitación negativa respecto del juicio de conocimiento en tanto juicio lógico. En el juicio de gusto "el fundamento de su determinación no puede ser sino subjetivo" $K U$, B 4. "Subjetivo", acorde con esta primera delimitación, se refiere a la posible validez del fundamento determinante del juicio, mientras que el fundamento mismo del juicio estético es la "conformidad a fin". Cfr. $K U, \S 10$ "De la conformidad a fines en general". 
derarlo desde el significado objetivo a considerarlo desde la posibilidad de comunicación. El arte abre tal posibilidad más allá del significado objetivo. Mientras en el juicio de conocimiento se establece una "realidad objetiva", la objetividad, en el juicio de gusto se comunican "objetividades móviles", símbolos, obras que abren valoraciones y perspectivas (acerca de lo dado sensiblemente). Aquí el juicio no es necesario y universal sino que comunica posibilidades orientadas por las ideas estéticas. Ahora en el lugar del objeto aparece "otra cosa", que da qué pensar; referirse a algo ahora es entonces "abrir posibilidades". ${ }^{47}$ Aquí, ahora, el significado no puede ser establecido como "realidad objetiva" (universal y necesaria) sino que se construye para nosotros, determinado "según la idea", ${ }^{48}$ la cual siendo la misma para todos es al mismo tiempo subjetiva (individual). Así, mediada por la referencia individual a la idea, la posibilidad de comunicación universal, se construye "más allá" del significado objetivo. El juicio aquí no determina objetos sino que reflexiona libremente a partir de las ideas realizadas estéticamente, las cuales "dan para pensar infinitamente" ${ }^{49}$ En la obra de arte se realiza la subjetividad como libertad. Pero en la caracterización de "subjetivo" en el juicio de gusto se halla ya simultáneamente implicada la remisión a una comunidad de sujetos. ${ }^{50}$ En la obra de arte se muestra la posibilidad de entenderse universalmente. En el juicio de gusto-se halla ya simultáneamente implicada la remisión a una comunidad de sujetos. De este modo se señala desde una perspectiva trascendental el fundamento de la sociabilidad humana, ya que "humanidad significa [...] la facultad de poder comunicarse íntima y universalmente". ${ }^{51}$ Esta estructura que acabamos de considerar,

47 De este modo el arte se transforma en una especie de orientación vital puesto que en la producción o juicio de las obras de arte al mismo tiempo "me vuelvo consciente de que ellas son productos, posiciones subjetivas y las capto como posibilidades a las cuales puedo orientar mi vida aun cuando no sean como objetos para ser conocidos o como perspectivas éticas para ser fundadas", U. Müller, "Objektivität und Fiktionalität", en Kant-Studien, no. 77, 1986, p. 212.

48 Cfr. H. Gadamer, op. it., p. 475.

$49 K U, \mathrm{~B} 192$.

50 Tal como señala U. Müller, agregando: "Tal empleo de la palabra subjetivo no es (o al menos no completamente) consciente para Kant, pero podemos estar autorizados a sacar estả consecuencia", U. Müller, "Objektivität und Fiktionalität", en Kant-Studien, no. 77, 1986, p. 205. "La explicación del concepto kantiano de subjetividad estética demuestra sus relaciones indirectas con un concepto de intersubjetividad no expresamente nombrado como tal, que sin embargo debe ser pensado en él." U. Müller, op. it., p. 205. A su vez, "La relación de la parte referida al entendimiento y la parte no referida al entendimiento, representada por la imaginación, la relación de estas dos maneras de representar es lo que da la posibilidad de comunicabilidad universal de las representaciones estéticas. En este sentido habría una 'objetividad' estética que en un sentido 'débil' es comprendida como intersubjetividad." U. Müller, op. cit., p. 207.

$51 K U$, B 262. 
sintetizada en la idea de comunicación, corresponde en tanto símbolo al lenguaje. Por ello, análogamente, puede decirse entonces que el lenguaje en tanto símbolo "da qué pensar".

\section{La reflexión trascendental acerca del lenguaje}

En lo que sigue, mencionaré, prácticamente en forma de tesis, algunas de las conclusiones que creo se pueden establecer a partir de lo expuesto respecto de la reflexión trascendental acerca del lenguaje en la facultad de juzgar reflexionante estética.

1) La reflexión llevada a cabo en la Crítica de la facultad de juzgar permite afirmar que la tesis del "silencio" de Kant respecto del lenguaje es falsa; ya que esta obra muestra una consideración explícita respecto del mismo. ${ }^{52}$

2) Esta concepción acerca del lenguaje está fundada en la perspectiva trascendental. La reflexión acerca del lenguaje desarrollada en el contexto de la facultad de juzgar reflexionante estética es trascendental. Es decir, Kant sólo se refiere indirecta y brevemente al lenguaje justamente porque las relaciones establecidas en el lenguaje no pueden ser concebidas en forma universal y necesaria. En el sentido kantiano del término, "trascendental", podrían ser denominados estrictamente, junto a las formas puras de la intuición, solamente aquellos conceptos bajo cuyo supuestos puede pensarse que las cosas, universalmente y en cuanto tal, pueden llegar a ser objeto de conocimiento. ${ }^{53}$ "Trascendental" designa, pues, los conceptos puros en la medida en que se refieren no a objetos particulares sino "al objeto como tal" en tanto éste puede ser pensado y del cual se abstrae en consecuencia todo rasgo que pudiera caracterizarlo particularmente. La lógica trascendental trata de la posibilidad del conocimiento en tanto tal y deja abierta e indeterminada las distintas formas de conocimientos particulares, referidas a su vez a objetos particulares. En este sentido el planteo trascendental no se ocupa (ni debería hacerlo) con "objetos"

52 Junto a otros textos a los cuales no me he referido en este trabajo.

53 "Trascendental" nombra: "todo conocimiento que se ocupa en general no tanto con objetos sino con nuestro modo de conocimiento en tanto éste debe ser posible a priori", KrV, B 25; en el mismo sentido se lee en la Crítica de la facultad de juzgar: "Un principio trascendental es aquel a través del cual 'es representada' a priori la condición universal bajo la cual exclusivamente las cosas pueden llegar a ser en general objetos de nuestro conocimiento." $K U$, B XXIX. Una discusión actial de dicho concepto en: T. Pinder, "Kants Begriff der transzendentalen Erkenntnis", en Kant-Studien, no. 77, 1986, pp. 1-40. Cfr. también $H$. Cohen, Kants Theorie der Erfahrung, 3a. ed., Berlín, 1918, pp. 89, 94, 108, 179 ss., 349 y 737 s. 
particulares, por lo tanto tampoco con el lenguaje (como un "objeto" particular entre otros).

Por ello sostenemos que la aparición sólo tangencial de una reflexión explícita acerca del lenguaje en Kant no debe ser interpretada sencillamente como una omisión o como la consideración del lenguaje como un tema de menor importancia junto a otros que, hasta cierto punto, igualmente podrian o no mencionarse. Antes bien, esta aparición sólo tangencial obedece a razones intrínsecas a la perspectiva trascendental, como dijimos, ésta se halla primariamente referida al conocimiento. Todo ello muestra entonces que no se trata de "olvido" o "silencio" respecto del lenguaje sino de una poisición respecto de su valor teórico en el contexto de los problemas propios que se plantea la investigación trascendental.

3) La reflexión acerca del lenguaje desarrollada en la facultad de juzgar reflexionante estética complementa la posición de Kant respecto del lenguaje expuesta desde el punto de vista del equilibrio conceptual del sistema crítico tal como él mismo lo formula. En ella Kant: a) expone explícitamente el tema del lenguaje de una manera algo más detallada que en otros textos; b) propone el modelo de la reflexión sobre el arte como juicio reflexionante, como una forma de comprender el lenguaje; y c) ofrece una reflexión sobre el sistema crítico en su conjunto en la cual ubicar la consideración acerca del lenguaje.

4) La reflexión acerca del lenguaje explicitada en la facultad de juzgar reflexionante estética brinda una consideración acerca del lenguaje que desarrolla la perspectiva trascendental acerca del mismo más alla del marco de la Crítíca de la razon pura. Dicha reflexión puede comprenderse como una determinación ulterior del concepto de lenguaje al ofrecido por la Crítíca de la razón pura. En ella se abre una nueva perpectiva que prosigue, profundiza y amplía el horizonte de la reflexión kantiana acerca del lenguaje: horizonte desde el cual se plantea una suerte de "dialéctica" entre significado y comunicación. La teoría del significado de Kant se asienta en el "giro copernicano". La posibilidad de objetividad, en la cual se centra la Crítica de la razón pura, es un eslabón de un movimiento teórico que indica la posibilidad de construcción de la significatividad a partir de la subjetividad. ${ }^{54}$ En la Crítica de la facultad de juzgar, supuesto dicho mundo objetivo, se trata de la construcción de mundos posibles en la esfera de la creación artística, y de las posibilidades que ésta encierra según la perspectiva 
trascendental. ${ }^{55}$ En el primer caso, entre el entendimiento y la sensibilidad media el esquema, en el segundo, el símbolo. Según la Crítica de la facultad de juzgar, dada la imposibilidad de intuir directamente el objeto quedan abiertas las posibilidades de intuir indirectactamente, es decir, de pensar analógicamente y de comunicarse. Pero con ello entonces se afirma, desde el punto de vista trascendental, la legitimidad de la diversidad de interpretaciones posibles sostenidas en el juicio de gusto. Según la Crítica de la facultad de juzgar, el juicio reflexiona a partir de símbolos y establece analogias que son diversos, sin tratarse de una diversidad meramente empírica. En este sentido la analítica de lo bello ofrece un modelo para comprender la diversidad lingüística en el marco de una consideración racional pura, no determinante sino reflexionante. Desde este punto de vista el lenguaje en tanto símbolo da qué pensar. La reflexión filosófica de Kant acerca del lenguaje, en tanto idealismo trascendental, deja necesariamente abierta, entonces, la posibilidad de comprender el lenguaje como lo que va "más allá" del mundo como significado, es decir, deja abierta la posibilidad del símbolo, en tanto éste testimonia lo inexpresable.

5) A partir de la la reflexión acerca del lenguaje desarrollada en la facultad de juzgar reflexionante estética se pueden extraer conclusiones respecto del problema del lenguaje en Kant y de las relaciones entre la reflexión de Kant acerca del lenguaje y la reflexión filosófica actual luego del "giro lingüístico". Lo que hemos visto sirve como una indicación para poder pensar que la teoría crítica incluye una posición filosófica respecto del lenguaje. Posición filosófica que asigna un valor diferente al lenguaje para la reflexión filosófica que el que le es atribuido por la filosofía orientada lingüísticamente. En este sentido el lenguaje es ubicado en la óptica de la crítica de la razón pura, precisamente con cuya formulación en la perspectiva de la facultad de juzgar comienza la obra que culmina el trabajo crítico. ${ }^{56}$

55 Como ejemplo de esta conexión en la teoría puede verse la articulación del concepto de comunicación con el de síntesis: "Sólo podemos comprender y comunicar a los otros aquello que nosotros mismos podemos hacer. Pues no podemos percibir la síntesis como dada, sino que nosotros mismos debemos hacerla, nosotros debemos sintetizar, si algo debe ser comprendido por nosotros como sintetizado. Sólo con vistas a esta síntesis podemos comunicarnos entre nosotros." Carta a Beck, 1.7.1794, AA, XI, 496.

56 "La capacidad de conocimiento a partir de principios a priori puede ser denominada la razón pura, y crítica de la razón pura la investigación de la posibilidad y límites de la misma en general" $K U, \mathrm{~B}$ III. 